\title{
Etnografi Ideasional \\ (Suatu Metodologi Penelitian Kebudayaan)
}

\author{
Mudjahirin Thohir \\ Fakultas Ilmu Budaya, Universitas Diponegoro \\ mudjahirinthohir@ymail.com
}

\begin{abstract}
Ideational ethnography is the study of society and culture based on the assumption that every action is meaningful to the perpetrators. The hidden meaning behind the motives is knowledge that is assumed to be true. The source of truth is belief (constitutive truth); reasoning and experience (cognitive truth), or evaluative reality as in tradition.

In ideational ethnographic research, the task of researchers is to seize the meaning referred to as the truth behind the cultural actions of the people studied. While the technique of digging data used is observation, interviews, and documents according to the context of the problem (reality) being studied.

In ideational ethnographic research, reality is seen in five levels, namely reality: empirical, symbolic, meaning, ideas, and values (worldview). How are the five realities seen from their perspective (emic perspective) as an example of sea ritual (labuh).
\end{abstract}

Keywords: ideational ethnography, culture, source of truth, level of reality, sea ritual (labuh).

\section{Intisari}

Etnografi ideasional adalah studi masyarakat dan kebudayaan berdasar asumsi bahwa setiap tindakan bermakna bagi para pelakunya. Makna tersembunyi di balik motif berupa pengetahuan yang dianggap benar. Sumber kebenaran itu bisa keyakinan (kebenaran konstitutif); penalaran dan pengalaman (kebenaran kognitif), atau kebenaan evaluatif seperti dalam tradisi.

Dalam riset etnografi ideasional, tugas peneliti adalah merebut makna yang diacu sebagai kebenaran di balik tindakan budaya masyarakat yang dikaji. Sementara teknik menggali data yang digunakan ialah observasi, wawancara, dan dokumen sesuai konteks masalah (realitas) yang dikaji.

Dalam riset etnografi ideasional, realitas itu dilihat ke dalam lima level yaitu realitas: empirik, simbolik, makna, ide, dan nilai (worldview). Bagaimana lima realitas itu dilihat dari kacamata mereka (emic perspective) sebagaimana contoh upacara laut.

Kata-Kunci: Etnografi ideasional, kebudayaan, sumber kebenaran, level realitas, sedekah laut.

\section{Pendahuluan}

Penelitian kebudayaan suatu masyarakat, baik mengenai produk-produk budayanya, atau perilaku budayanya, atau gagasan yang ada di balik perilaku maupun produknya, cenderung menunjukkan hasil yang beragam. Keragaman atas hasil penelitian itu, sangat 
dipengaruhi oleh paradigma yang digunakannya. Paradigma di sini, meliputi sisi ontologi, epistemologi, dan metodologinya.

Dalam dunia penelitian ilmiah, dikenal adanya dua paradigma berpikir yaitu berpikir menurut filsafat positivisme dalam satu segi, dan berfikir berdasarkan pandangan interpretif dalam segi yang lain. Pandangan interpretif ini merupakan ciri dasar dari penelitian etnografi. Di dalam penelitian etnografi, kebudayaan masyarakat dipelajari dengan menggunakan piranti kebudayaan masyarakat terkait, yakni secara emik. Dengan kata lain, etnografi merupakan istilah untuk menjelaskan bagaimana "teori" kebudayaan dipakai untuk mengkaji kebudayaan sebagai objek.

Tulisan ini akan menyajikan bagaimana melakukan penelitian sosial-budaya berdasarkan pada pendekatan kebudayaan (ethnografi) menurut teori ideasional dan metodologisnya, sehingga disebut sebagai Etnografi Ideasional. Pertanyaan-pertanyaan terkait dengan studi ethnografi ini ialah bagaimana kebudayaan dilihat sebagai pendekatan teoritik, dan pada saat yang sama bagaimana kebudayaan itu diposisikan sebagai subjek kajian. Sebagai pendekatan, kebudayaan akan ditelusuri lewat level-level pemaknaan. Berdasarkan pada level-level makna, berikutnya bagaimana mengaplikasikan sebagai Kajian Kebudayaan.

\section{Pengertian dan Aplikasi Kajian Kebudayaan}

\section{Tiga Level Makna Kebudayaan}

Ada tiga level pemaknaan bagaimana mengartikan kebudayaan. Pertama, kebudayaan sebagai istilah untuk merujuk dan menunjuk "pilihan tindakan dan keputusan (terlepas dari baik atau buruk) dari pilihannya itu, seperti ungkapan: "tidak disiplin, jam karet, dan korupsi, sudah menjadi budaya orang Indonesia". Ini adalah pengertian kebudayaan menurut orang awam. Kedua, arti kebudayaan itu merujuk pada "segala aktivitas yang berkaitan dengan estetika dan pemenuhan cita rasa keindahan sehingga kebudayaan itu (hanya) diidentikkan dengan ke-seni-an'. Pandangan ini memposisikan kebudayaan dalam arti sempit yaitu ekuivalen dengan kesenian. Sedang ketiga, kebudayaan sebagaimana teori ideasional ${ }^{1}$, dimaknai sebagai "keseluruhan cara hidup

\footnotetext{
${ }^{1}$ Tiga model teori pendekatan kebudayaan, yaitu materialisme, behaviorisme, dan ideasional. Dalam teori materialisme, disebut sebagai kebudayaan ketika ia sudah terwujud sebagai matters (benda-benda), seperti artifak, dan dokumen-dokumen lain yang nampak (tangible). Dalam teori behavioralisme, kebudayaan lebih dilihat pada pola-pola tindakan (patterns of behavior), sementara
} 
suatu masyarakat di dalam beradaptasi dan untuk hidup secara adaptif terhadap lingkungan alam dan lingkungan sosial”.

Dalam teori ideasional ini, kebudayaan dilihat dalam fungsinya sebagai pola-pola untuk melahirkan tindakan (patterns for behavior) bukan pola-pola dari tindakan (pattern of behavior), sebagaimana pandangan Kluchohn yang dikutip Cliford Geertz (1973: 4-5) berikut:

CULTURE
(Clyde Kluchohn: Mirror for Man)

- The total way of life

- A way of thinking, feeling, \& believing;

- An abstraction from behavior;

- The way in which a group of people in fact behave;

- A "store house of pooled learning;

- A set of standardized orientations to recurrent problems;

- "Learned behavior";

- A mechanism for the normative regulation of behavior;

- A set of techniques for adjusting both to the external environment $\&$ to other men;

- A precipitate (endapan) of history; \& turning, perhaps in desperation, to simile as a map, as a sieve (saringan), and as a matrix. (see Geertz, 1973. The Interpretation of Cultures. P. 4-5)

Etnografi ideasional dalam judul tulisan ini diarahkan kepada penelitian kebudayaan, di mana kebudayaan dimaknai sebagai satuan ide masyarakat manusia sebagai patterns for behavior dimaksud. Pertanyaan yang kemudian dijabarkan ialah bagaimana metodologi penelitian kebudayaan (etnografi) dipakai sebagai alat menggali ide (pengetahuan dan keyakinan) masyarakat sehingga melahirkan tindakan-tindakan yang berpola, termasuk produk-produk (artifak) sebagai hasil tindakan?

\section{Etnografi sebagai Kajian Kebudayaan}

Ada dua penjelasan apa itu etnografi. Pertama adalah nama untuk suatu metodologi penelitian lapangan (field work study) yang dilakukan secara mendalam; kedua sebagai jenis laporan penelitian (ethnographic writting).

Sebagai suatu nama metodologi penelitian kebudayaan, berarti etnografi dijalankan dengan bertumpu pada bagaimana kebudayaan itu dimaknai. Jika kebudayaan di sini dilihat berdasarkan teori ideasional, maka etnografi ideasional akan dicirikhasi pada cara

pada teori ideasional, menempatkan pengertian kebudayaan pada gagasan (ide) seperti pengetahuan dan keyakinan yang dipakai sebagai landasan tingkah laku dan produk. 
bagaimana dunia kehidupan itu dipahami secara verstehen dan mendalam (tick description).

Verstehen mengacu pada upaya pemahaman, baik niat maupun konteks tindakan-tindakan manusia. Ia termasuk bagaimana memasuki pikiran orang lain (the others) dan nalar yang mendorong tindakan. Untuk memahami dan memaknai tindakan ritual yang terjadi misalnya, kita harus memiliki akses pada pikiran, niat, dan perspektif pelakunya, bukan hanya interpretasi orang-orang luar pada tindakantindakan itu" (lihat Malkasian, 2003).

Sedang tick description, atau lukisan mendalam dimaksudkan bahwa kebudayaan masyarakat manusia itu berada dalam suatu jaringan makna sehingga untuk memahaminya, haruslah dengan pemahaman yang mendalam sebagaimana penjelasan Clifford Geertz berikut.

".. Ethnography is thick description. What the ethnographer is in fact faced with except when (as of course, he must do) he is pursuing the more automatized routines of data collection - is a multiplicity of complex conceptual structures, many of them superimposed upon or knotted into one another, which are at once strange, irregular, and inexplicit, and which he must contrive somehow first to grasp and then to render... (Geertz, 1973).

Pendekatan sosial-budaya yang berciri verstehen dan lukisan mendalam (tick description) ini, dapat diartikan sebagai sudut pandang atau cara melihat dan memperlakukan sesuatu gejala yang menjadi perhatian --- dengan menggunakan kebudayaan. Dengan demikian, konsep kebudayaan di sini dilihat dalam dua sisi. Dalam satu sisi, ia adalah subyek dari gejala yang dikaji seperti dalam hal ini pola hidup bersih dan kesadaran atas lingkungan bersih, dan dalam sisi yang lain, ia adalah alat untuk acuan atau kacamata dalam melihat, memperlakukan, dan menelitinya. Iknas Kleden, menganalogikan sebagai berikut.

Kebudayaan adalah selembar kain yang akan dijahit menjadi baju oleh seorang tukang jahit, tetapi dari segi lain, kebudayaan adalah pola yang menjadi contoh dan pedoman bagi si penjahit dalam bekerja. (Kleden, 1987)

Berdasarkan pada teori ideasional itu, kebudayaan ditempatkan sebagai keseluruhan sistem-sistem gagasan yang terwujud sebagai pengetahuan dan keyakinan yang kegunaannya fungsional yaitu sebagai acuan bertindak atau sebagai blueprint. 
Sebagai keseluruhan pengetahuan dan keyakinan, kebudayaan berisi perangkatperangkat model-model pengetahuan yang secara selektif digunakan oleh para pelakunya untuk menginterpretasi dan memahami realitas sosial budaya masyarakat.

\section{Etnografi Ideasional}

Realitas sosial budaya masyarakat, sepintas tidak nampak sebagai berstruktur bahkan oleh sebagian orang dianggap tanpa struktur. Kacau balau, arbitrer, dan rumit. Pandangan ini, memang tidak sepenuhnya salah, tetapi yang justru menjadi persoalan ialah bagaimana menemukan jawaban terhadap kondisi yang kaca-balau, arbitrer, dan rumit itu?

Dalam kajian yang bergerak pada filsafat positivisme, realitas yang rumit demikian dijawab dengan cara menyederhanakan begitu saja seakan realitas itu bisa dikendalikan oleh penelitinya sendiri. Hal ini nampak dari model mencari jawaban atas masalah yang diajukan melalui hubungan variabel pengaruh (independent variable) dengan variabel terpengaruh (dependent variable). Suatu keadaan terjadi oleh pengaruh dari keadaan lain. Dari sini lantas diajukan hipotesis, dan formula atau dalil-dalil statistik. Nalar keilmuan seperti ini lebih mengedepan daripada fakta-faktanya sendiri yang ingin ditemukan.

Apa yang terjadi? Dibuatlah sejumlah daftar pertanyaan (tentu dibayangkan) sebagai alasan pembuktian apakah dalil statistik dan hipotesis yang diajukan terbukti atau tidak. Inikah yang kemudian hasilnya disebut sebagai kebenaran ilmiah? Jika dijawab "ya", maka peng-iya-kan tadi, lebih pada alat mengukur, bukan pada substansi realitas yang mau diukur.

Lain halnya dengan paradigma interpretif sebagai inti dasar dari kerangka berfikir etnografi ideasional. Realitas sosial budaya dalam paradigma interpretif, adalah kompleks dan subketif karena berada dalam tataran masyarakat itu sendiri. Karena kompleksitas itulah lalu para peneliti yang bermazhab interpretif, melihat lebih awal lapis-lapis realitas. Tanpa melihat atau mengabaikan lapis-lapis realitas yang ada, maka hasilnya hanyalah permukaan saja.

Ada lima lapis realitas sosial budaya masyarakat yang mesti dipahami secara benar bagi setiap peneliti yang menggunakan acuan atau mengatasnamakan sebagai penelitian etnografi ideasional. Lima lapis realitas itu dapat digambarkan sebagai berikut. 


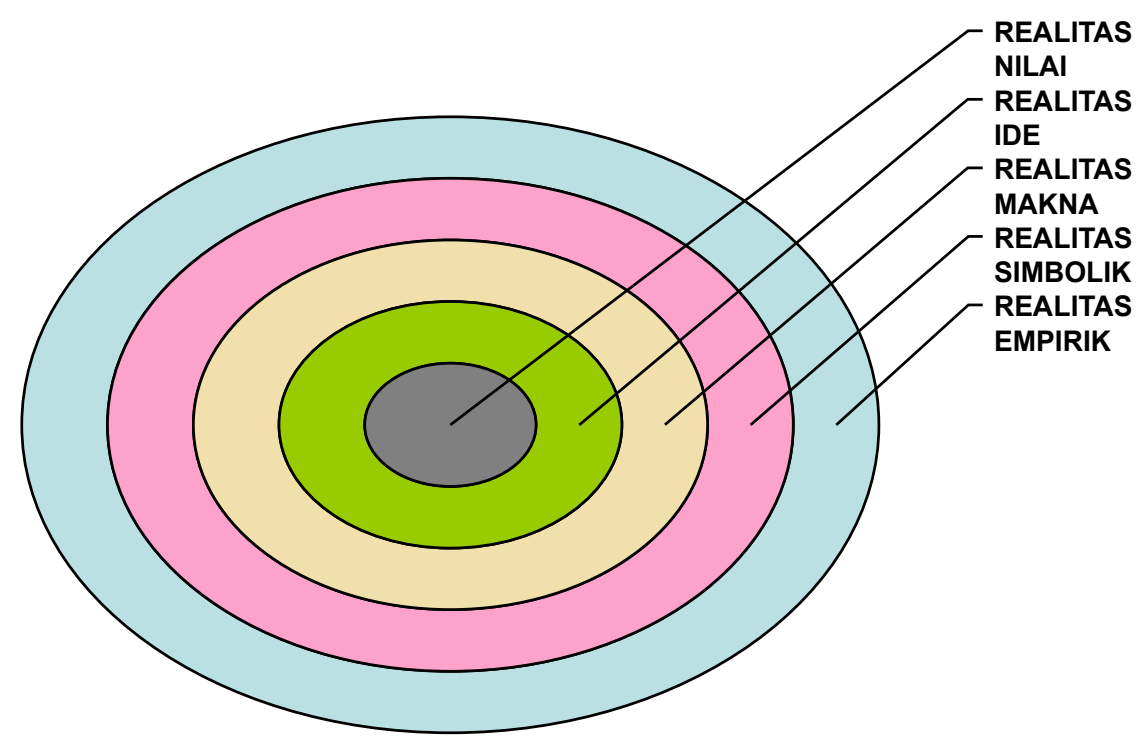

Realitas pertama, yang nampak (tangible) adalah realitas empirik. Dalam realitas empirik ini, dunia kehidupan sepertinya memang "tidak teratur", tanpa struktur, alias kacau-balau. Tetapi sesungguhnya, dengan kepekaan intelektualitas yang dimiliki peneliti, realitas empirik itu memiliki pola (patterned). Pola di sini, bisa sudah ada sebagai hasil konstruksi, seperti pola bangunan fisikal, atau pola kegiatan ritual, dan semisalnya. Tetapi bisa saja, masih tersembunyi atau tersamar, dan ketersembunyian demikian itulah yang justru menjadi tugas peneliti untuk menstrukturkan. Inilah yang disebut dengan realitas simbolik. Lihat misalnya pada bangunan setiap upacara, maka akan kita temukan pola yang cenderung menetap, yakni ada peserta upacara yang terdiri dari: peserta, petugas, dan pemimpin upacara. Masing-masing akan menempatkan diri dalam posisi yang berbeda karena status dan peran yang dimainkan berbeda. Inilah lapis realitas kedua yaitu realitas simbolik.

Realitas ketiga ialah realitas makna. Dikatakan sebagai realitas makna sebab sebab realitas itu bermakna (the reality is meaningfull). Makna menurut pelakunya maupun makna menurut pengamatnya. Karena dua kemungkinan itu, maka di dalam penelitian etnografi ideasional, akan mempertimbangkan dialog-dialog antara peneliti dan masyarakat yang diteliti, untuk menemukan jawaban yang mendekati ketepatan, berdasarkan perspekktif emic-etic secara berulang. 
Mengapa berdialog dan men-dialog-kan dalam penelitian etnografi ideasional begitu penting? Tidak lain adalah untuk menemukan inti gagasan yang mendorong atau terwujud sebagaimana yang kita pahami. Inilah realitas keempat yaitu realitas ide, semacam logika sekaligus cara bagaimana tindakan yang dipilih sesuai dengan tujuan yang ingin dicapai. Untuk menemukan ide-ide (kebenaran), perlu didialogkan dan mendialogkan secara mendalam objek kajian sebagai subject matter kepada para pihak (triangulation dialogue) antara masyarakat (pelaku, aktor), referensi (teori yang relevan) dan peneliti. Variasi pemaknaan dan kedalamannya, sangat dipengaruhi oleh tingkat kualitas pemahaman, intensitas perhatian, dan daya-daya eksternal lain bagi diri para aktor terhadap objek atau peristiwanya. Dalam sebuah peristiwa ritual sosial keagamaan misalnya (sebagai contoh kasus), partisipan di dalamnya ada yang larut secara emotif sampai meneteskan air mata, tetapi sebagian yang lain malah bicara sendiri dengan teman sebelahnya. Untuk menemukan jawaban-jawaban tepat atas pertanyaan, mengapa? Maka mempertemukan kepaduan pemahaman antara: referensi, masyarakat sebagai pelaku dan peneliti sebagai pengkaji menjadi sangat penting. Dalam bentuk skematik, mempertemukan itu sebagau berikut.

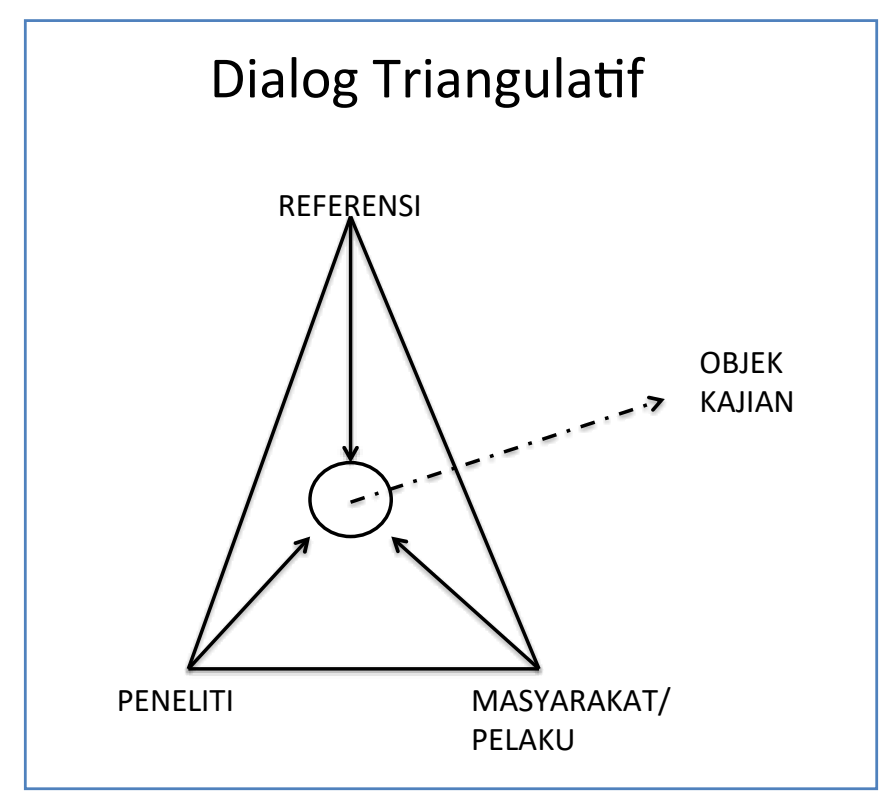

Dalam suat

Pencapaian seperti apa, merupakan jawaban final yang harus ditemukan di balik setiap kelakuan manusia. Inilah realitas kelima yang disebut realitas nilai atau worldview. 
Dalam realitas nilai atau worldview, di sana akan ditemukan asumsi dasar sebagai inti kebudayaan, yakni sesuatu yang diyakini benar lawan yang salah, dan sesuatu yang baik lawan yang buruk.

Yang inti dari setiap kebudayaan demikian itu, dalam diri masyarakat manusia itu sendiri, sumbernya bisa beragam. Masing-masing sumber bisa selaras dan menyelaraskan, tetapi bisa juga saling bertabrakan. Karena itu, tidak aneh kalau dalam kehidupan sosialbudaya masyarakat, ada damai ketika selaras, dan ada ketegangan bahkan konflik kalau ada tabrakan. Sumber-sumber yang dijadikan acuan dimaksud ialah seperti skema berikut.

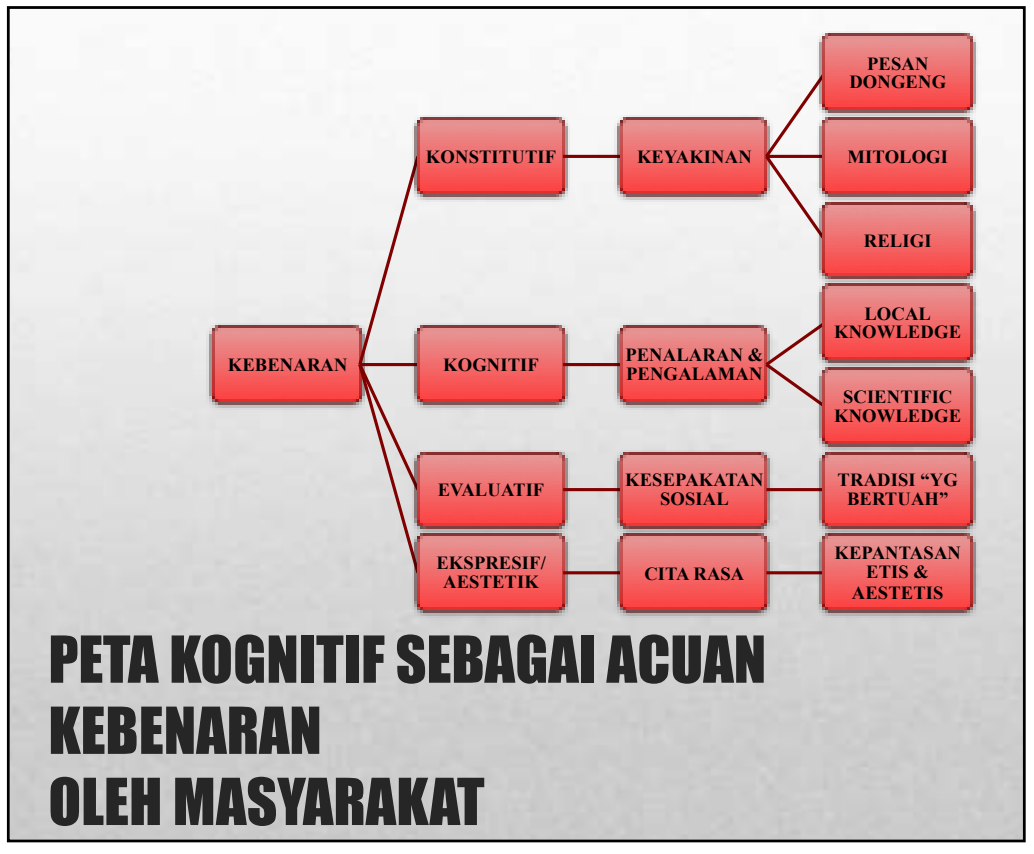

Apa yang dianggap benar karena itu dijadikan sumber nilai (value) bagi masyarakat, berangkat dari keyakinan sehingga yang diyakini itu pasti benar bagi pelakunya (kebenaran konstitutif) sebagaimana kebenaran agama, atau mitologi, atau dari pesan dongeng. Atau bisa karena pengalaman yang dinalarkan (kebenaran kognitif) seperti di dalam kebenaran ilmiah maupun dalam pengetahuan lokal masyarakat. Kalau tidak karena alasan itu, kebenaran itu juga bisa 'bersemayam' di balik kesepakatan sosial seperti dalam adat-istiadat. Di luar soal-soal kebenaran (nalar) adalah ketepatan rasa, seperti dalam konstruksi kepantasan sosial dan keindahan (kebenaran ekspresif).

Bobot dan selera masing-masing orang dalam menenntukan pilihan tindakan, tidak akan lari jauh dari pertimbangan-pertimbangan dari keempat jenis acuan kebenaran 
sebagaimana skema di atas. Dari sinilah tugas seorang peneliti yang bergerak pada penelitian etnografi ideasional berproses.

\section{Pengamatan dan Pemahaman dalam Etnografi Ideasional}

Upacara Labuh yakni ritual terkait dengan selamatan laut oleh sebagian masyarakat, khususnya bagi para nelayan yang mengais rizki di laut Jawa bagian selatan, yang dilaksanakan pada setiap tanggal 1 syuro, menurut hitungan kalenderial Jawa, bisa menjadi contoh bagaimana etnografi ideasional mempelajari lapis-lapis realitasnya berdasarkan acuan-acuan kebenaran yang digunakan oleh pelaku yang ada di dalamnya.

Di dalam realitas empirik, kita melihat sejumlah orang sesuai dengan peran dan tugasnya masing-masing. Sebagian membawa sesaji, sebagian melakukan doa dan mantramantra, dan sebagian yang lain menghantarkan sesaji itu ke tengah laut untuk disampaikan kepada pihak-pihak tertentu, khususnya kepada penguasa laut, dan dilakukan dengan caracara khusus pula. Rangkaian berbagai kegiatan upacara ritual Labuh itu, dapat dilihat dari potongan-potongan gambar sebagai berikut.

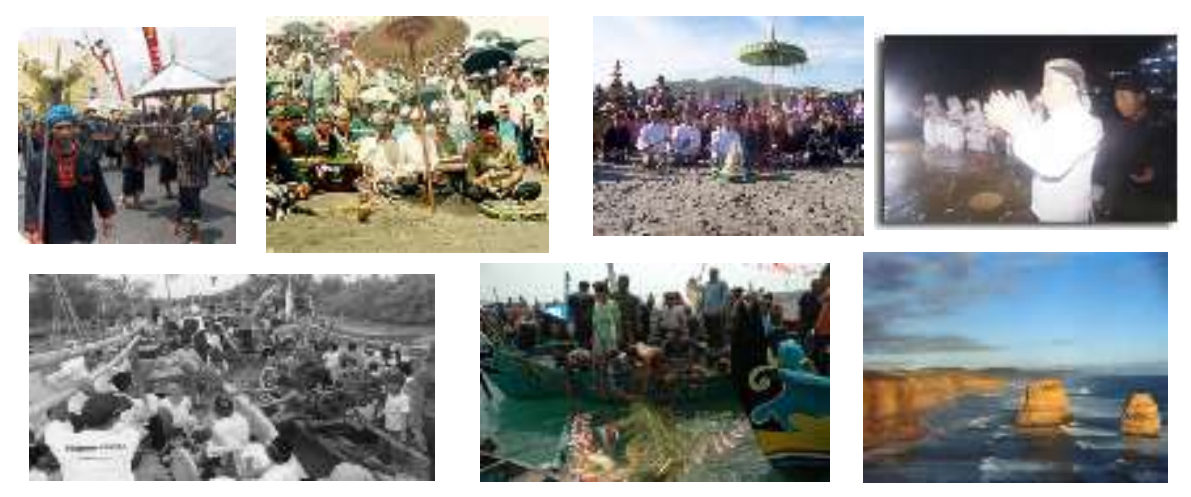

Serangkaian tindakan yang terpola sebagaimana gambar di atas, bermakna, beride, dan bernilai dalam tataran keseimbangan dan keberlangsungan kehidupan secara adaptif resiprositatif antara dirinya dengan pihak yang dituju, yaitu penguasa laut itu sendiri. Siapa figur itu? Dalam konstruksi kognitif, konstitutif, dan evaluatif, serta ekspresif adalah “penjaga laut selatan”, sehingga disebutnya sebagai Ratu Kidul atau Ratu Selatan, yang sosoknya (mungkin secara imajiner) dilukiskan sebagai gambar berikut. 


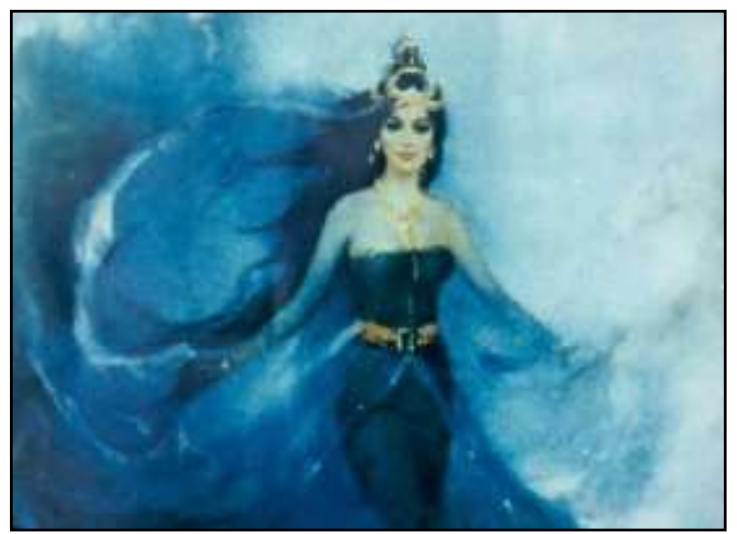

Hubungan resiprositas antara masyarakat (khususnya nelayan) kepada Ratu Kidul ini, jika dilihat secara "triangulasi" adalah sebagai berikut.

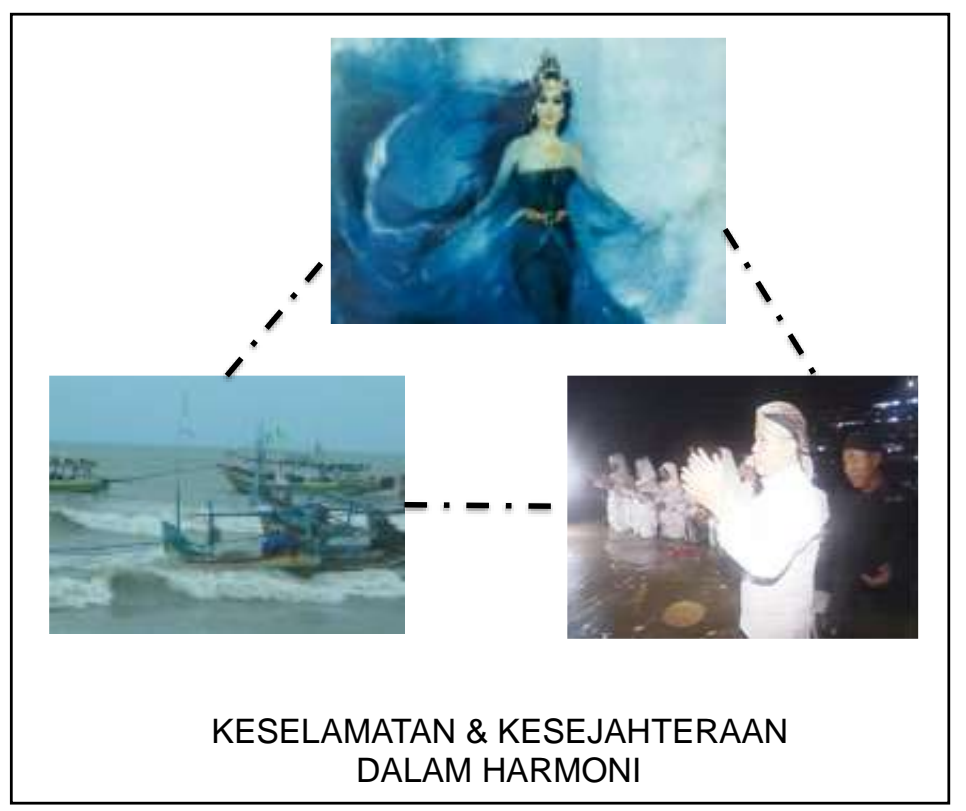

Untuk analisis etnografi ideasional, akan melahirkan konstruksi pemahaman akan praktik-praktik budaya yang menjelaskan adanya makna-makna, ide-ide, dan nilai-nilai sebagaimana analisis tematik berikut. 
PEMAHAMAN EKSISTENSI MITOS RATU KIDUL

BAGI NELAYAN DI BALIK RITUAL LABUH

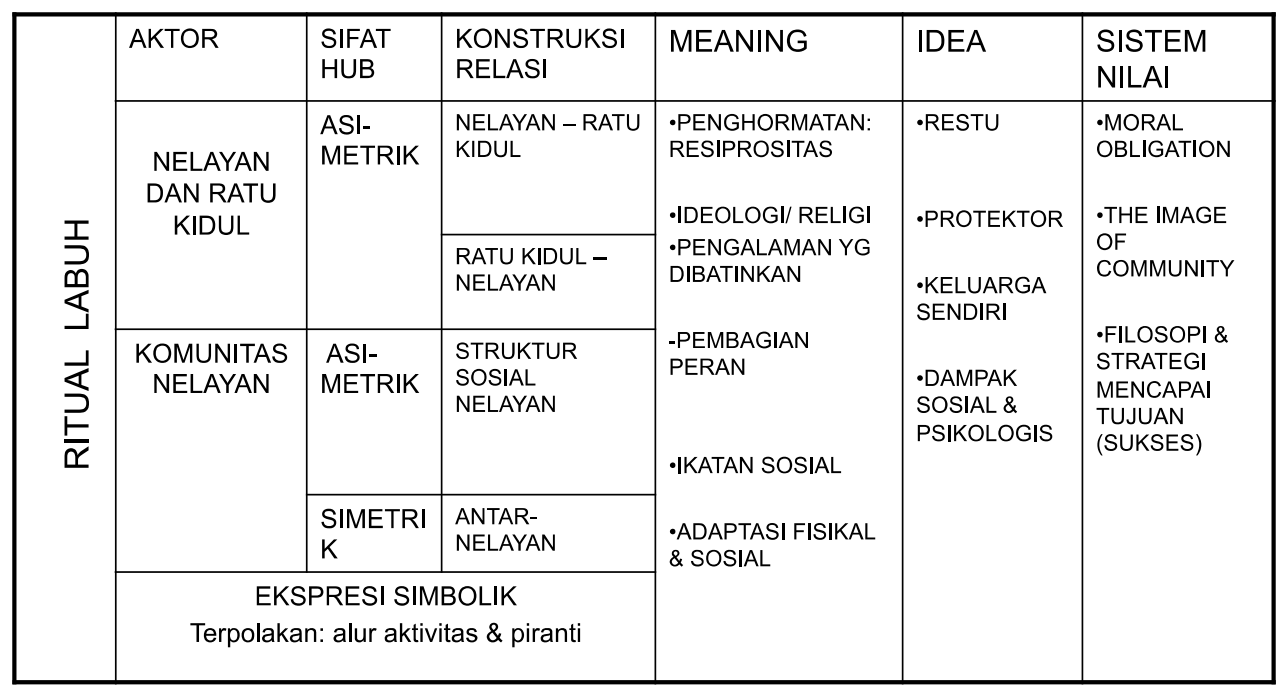

Lahirnya konstruksi budaya demikian, terjadi melewati proses-proses pembudayaan secara berkelanjutan, sehingga dalam diri masing-masing orang, memahami, menjalankan, mentradisikan, dan mengidentifikasikan diri dalam satuan sosialnya. Inilah proses pembudayaan berdasarkan nalar kebudayaan ideasional, seagaimana sketsa berikut.

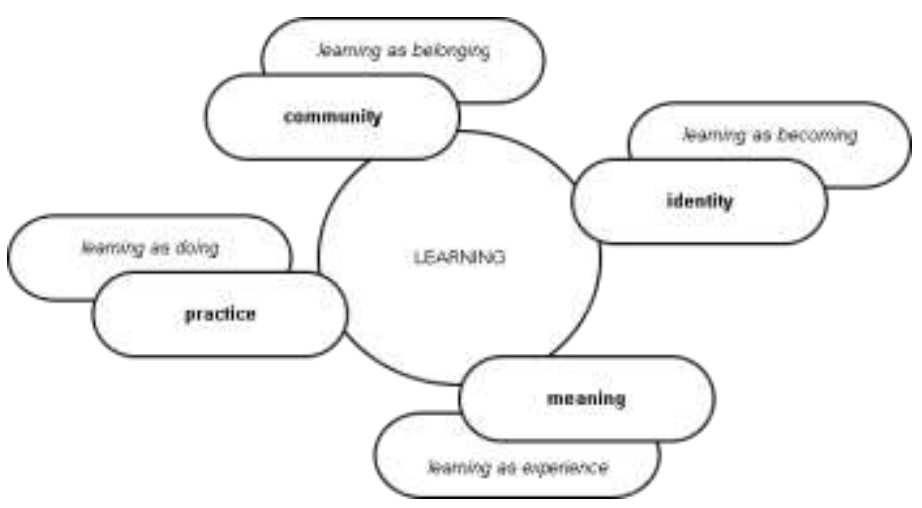

\section{Simpulan}

Sebagaimana dalil utamanya, bahwa meneliti suatu masyarakat termasuk kebudayaan yang ada di dalamnya, berarti mempelajari sehingga bisa mengerti mengenai berbagai realitas budaya yang ada. Pengertian budaya dimaksud, tidak cukup hanya mendiskripsikan apa yang ada di permukaan (surface structure), tetapi menyelam ke dalamnya, sehingga 
ditemukan realitas-realitas yang tersembunyi (back stage) di belakangnya, seperti realitas makna, realitas ide, dan realitas nilai.

Proses untuk menemukan lapis-lapis realitas tadi, berpadu dan dipadukan secara emic dan etic untuk kemudian ditemukan jawaban kuncinya berdasarkan acuan-acuan kebenaran, yaitu perpaduan kebenaran konstitutif, kogniti, evaluatif, dan ekspresif. Mencari, mengamati, menemukan, dan menyajikan secara khusus demikian inilah inti dan proses dari apa yang saya maksud sebagai etnografi ideasional. Semoga!

\section{Daftar Pustaka}

Geertz, Clifford. 1973. Interpretation of Cultures. New York: Basic Group.

Kleden, Egnas. 1987. “Kebudayaan Bukanlah Ideologi. Kompas, 25 Juni

Kluckhohn, Clyde dan O.H. Mowrer. 1944. "Culture and personality”: a Conceptual Scheme", dalam American Anthropologist. January-March. Vol. 46, No. 1, part 1

Malkasian, Sophia. 2003. "Bersikeras untuk Mati? Catatan Orang-orang Eropa tentang Kekerasan di Indonesia di Masa Pra-Kolonial" dalam http://www.scripp.ohiou.edu/news/cmdd/artikel sm.htm

Moeran, Brian. 2006. Ethnography at Work. New York: Berg.Schwartz, Shalom H. 2007. "A Theory of Cultural Value Orientation: Explication and Applications", dalam Esmer, Yilman dan Thorleif Petterson (eds). Measuring and Mapping Cultures: 25 Years of Comparative Values Surveys. Boston: Brill. Hlm. 33-78.

Thohir, Mudjahirin. 2013. Multikulturalisme: Sastra, Budaya, dan Agama. Semarang: Gigih Pustaka Mandiri.

Thomas, Helen Thomas and Jamilah Ahmed. 2004. (Eds) Cultural bodies : ethnography and theory. Blackwell Publishing Ltd. 